Review

\title{
Efficacy and safety of immunological adjuvants. Where is the cut-off?
}

\author{
Alexander Batista-Duharte*, Damiana Téllez Martínez, Iracilda Zeppone Carlos \\ São Paulo State University (UNESP), School of Pharmaceutical Sciences, Department of Clinical Analysis, Rod. Araraquara-Jaú-Km 1, CEP: 14801-902, Araraquara, São \\ Paulo, Brazil
}

\section{A R T I C L E I N F O}

\section{Keywords:}

Adjuvants

Vaccine

Safety

Immunotoxicity

Efficacy

\begin{abstract}
A B S T R A C T
Research over the past several decades has provided insight into the mode of action of adjuvants. However, the main focus of attention has been the efficacy in the induction of protective immunogenicity, while less effort has been devoted to the study of toxicity mechanisms. Evidences suggest that several mechanisms that are responsible for the immunostimulating effects are, at the same time, responsible of the adverse effects. In this context, it is often very difficult to establish the boundaries between immunostimulation and immunotoxicity to reach the ideal balance of efficacy/safety. During decades, hundreds of adjuvants and adjuvant formulations have been proposed as immunostimulants for vaccines but very few have been used in human vaccines due to toxicity concerns. In this review, relevant aspects about immunotoxicology of adjuvants, based on clinical and experimental studies are discussed. Some effects are only observed under hyperstimulating regimens using nonapproved adjuvants for human use, but these are nonetheless useful to understanding basic principles of adjuvant toxicity. The acute local and systemic reactions, during the first hours and those that can be observed after the third day of vaccination in the inoculation site and systemically are discussed.
\end{abstract}

\section{Introduction}

Adjuvants are essential for efficacy of most vaccines [1]. Historically, the focus of attention in adjuvant research has been the efficacy in the induction of protective immunogenicity, while less effort has been devoted to the study of toxicity mechanisms [2]. However, vaccine safety is currently a key concern of regulatory agencies and health institutions. Regrettably, the vast majority of toxicity studies with adjuvants were performed in combination with a wide variety of antigens. Thus, information about the toxicity of adjuvants alone is scarce, hampering the understanding of the mechanisms involved in several adverse events [3].

The physicochemical properties of adjuvants, the antigenic structure, the doses, the frequency and route of administration, as well as the genetic characteristics of the organism, are determinant conditions that influence the quality of the immune response [4,5]. In the same way, these factors influence the toxicity reactions of the adjuvanted vaccines. Nowadays, it is accepted that many adverse reactions induced by immunological adjuvants occurs through an immunological-based mechanism (Table 1). The immunostimulatory effects that are necessary to increase the effectiveness of the vaccine can lead to undesirable effects if exceeding certain limits (Fig. 1). However, for immunological adjuvants, the limits between the desired pharmacological effects and toxicity are often imprecise $[2,3,6]$.

Currently, one of the greatest challenges in vaccine design is the use of highly effective antigen-adjuvant combinations while causing minimal adverse effects. Increasing insight into immunological mechanisms and how to manipulate them using molecules with well-defined mechanisms of action, has replaced empirical with rational design of adjuvants and targeted molecular modulation $[1,7,8]$.

In the following sections, the acute local and systemic immunotoxic reactions occurring during the first hours post-administration are analyzed. Following, those reactions that can be observed after the third day of vaccination in the inoculation site and systemically are also discussed (Fig. 2).

Several of the adverse effects mentioned here have been observed only under experimental conditions in laboratory animals, in veterinary vaccines or during different phases of clinical trials. Others have been reported in human prophylactic and therapeutic vaccines.

\section{Acute immunotoxic reactions induced by adjuvants}

After vaccination, the early innate immune responses that is stimulated in the inoculation site by the adjuvant, define the characteristics and magnitude of the adaptive responses as well as the vaccine efficacy and toxicity $[9,10]$. The acute immunotoxic reactions are those

\footnotetext{
* Corresponding author at: Faculdade de Ciências Farmacêuticas, Departamento de Análises Clínicas. Universidade Estadual Paulista Julio Mesquita Filho, (UNESP), Rod. AraraquaraJaú-Km 1, Campus Ville, Araraquara, São Paulo, CEP: 14800-903, Brazil.

E-mail address: batistaduhartea@fcfar.unesp.br (A. Batista-Duharte).
} 
Table 1

Some relevant mechanisms involved in vaccine adjuvant immunotoxicity.

\begin{tabular}{|c|c|c|c|c|}
\hline Mechanisms & Consequence & Clinical manifestations & $\begin{array}{l}\text { Adjuvant } \\
\text { examples }\end{array}$ & $\begin{array}{l}\text { Selected } \\
\text { References }\end{array}$ \\
\hline \multicolumn{5}{|l|}{ Associated with local reactions } \\
\hline Direct cytolytic & $\begin{array}{l}\text { Direct lytic effects on cells in the inoculation } \\
\text { site. Damage-associated molecular patterns } \\
\text { (DAMPs) release from injured cells. }\end{array}$ & Local irritation and inflammation & $\begin{array}{l}\text { Alum } \\
\text { Saponins }\end{array}$ & {$[11,14,15,16]$} \\
\hline Depot effect and slow degradation & $\begin{array}{l}\text { Excessive recruitment of immune cells and } \\
\text { Th1-biased response }\end{array}$ & $\begin{array}{l}\text { Long lasting local inflammation, } \\
\text { granuloma (delayed-type } \\
\text { hypersensitivity) }\end{array}$ & $\begin{array}{l}\text { Gels } \\
\text { Emulsions }\end{array}$ & {$[17,96,63,64]$} \\
\hline Inflammation-associated oncogenesis & Tumorigenesis & Tumors in the inoculation site & Alum & {$[68,69,70,71,72,73,74]$} \\
\hline \multicolumn{5}{|c|}{ Associated with local and (or) systemic reactions } \\
\hline $\begin{array}{l}\text { Profuse release of inflammatory } \\
\text { cytokine/chemokines }\end{array}$ & $\begin{array}{l}\text { Excessive stimulation and/or suboptimal } \\
\text { downregulation of innate immune system }\end{array}$ & $\begin{array}{l}\text { Local inflammation, acute phase } \\
\text { response } \\
\text { Vascular leak syndrome } \\
\text { Aplastic-like bone marrow }\end{array}$ & $\begin{array}{l}\text { Multiple } \\
\text { Cytokines } \\
\text { pATRex }\end{array}$ & $\begin{array}{l}{[44,45]} \\
{[57,58,59,60]} \\
{[109,110]}\end{array}$ \\
\hline $\begin{array}{l}\text { Disturbs in hepatic cytochrome P450 } \\
\text { expression/activity mediated. } \\
\text { Changes in drug transporters }\end{array}$ & $\begin{array}{l}\text { Changes in pharmacokinetics (including } \\
\text { metabolism) and pharmacodynamics of } \\
\text { drugs mediated by cytokines }\end{array}$ & $\begin{array}{l}\text { Toxicity of some drugs administered } \\
\text { during or shortly after vaccination }\end{array}$ & $\begin{array}{l}\text { Freund's } \\
\text { adjuvants } \\
\text { Alum } \\
\text { LPS }\end{array}$ & {$[46,47,48,49,50,51,52,53,54]$} \\
\hline Off-target effect & $\begin{array}{l}\text { Expression of innate immune receptors by } \\
\text { cell types not involved in the immune } \\
\text { response }\end{array}$ & $\begin{array}{l}\text { Inflammation in non-immune } \\
\text { tissues. Autoimmune/inflammatory } \\
\text { symdrome associated to adjuvants? }\end{array}$ & Alum & {$[9,79]$} \\
\hline $\begin{array}{l}\text { Failure in the contraction of adaptive } \\
\text { immune response }\end{array}$ & $\begin{array}{l}\text { Homeostatic disturbances in several immune } \\
\text { mechanisms }\end{array}$ & $\begin{array}{l}\text { Hypersensibility reactions and } \\
\text { autoimmune disorders }\end{array}$ & $\begin{array}{l}\text { Freund's } \\
\text { adjuvants, } \\
\text { Alum. } \\
\text { Regulatory T } \\
\text { cells modulators }\end{array}$ & $\begin{array}{l}{[75,76,77,78,79,80]} \\
{[8]}\end{array}$ \\
\hline Loss of peripheral immunotolerance & Immune response against own tissues & Autoimmune process & $\begin{array}{l}\text { Freund's } \\
\text { adjuvants } \\
\text { Alum }\end{array}$ & {$[75,76,77,78,79,80]$} \\
\hline Excessive Th2-biased response & $\begin{array}{l}\text { Excessive stimulation of IgE response and } \\
\text { allergy mediators }\end{array}$ & $\begin{array}{l}\text { Immediate-type hypersensitivity } \\
\text { reactions }\end{array}$ & Alum & {$[27,30,32]$} \\
\hline $\begin{array}{l}\text { Formation and deposition of immune } \\
\text { complex (IC) }\end{array}$ & $\begin{array}{l}\text { Local or systemic inflammatory reactions } \\
\text { mediated by IC }\end{array}$ & Arthus reactions, vasculitis & Alum & {$[26,27,28,29,30]$} \\
\hline
\end{tabular}

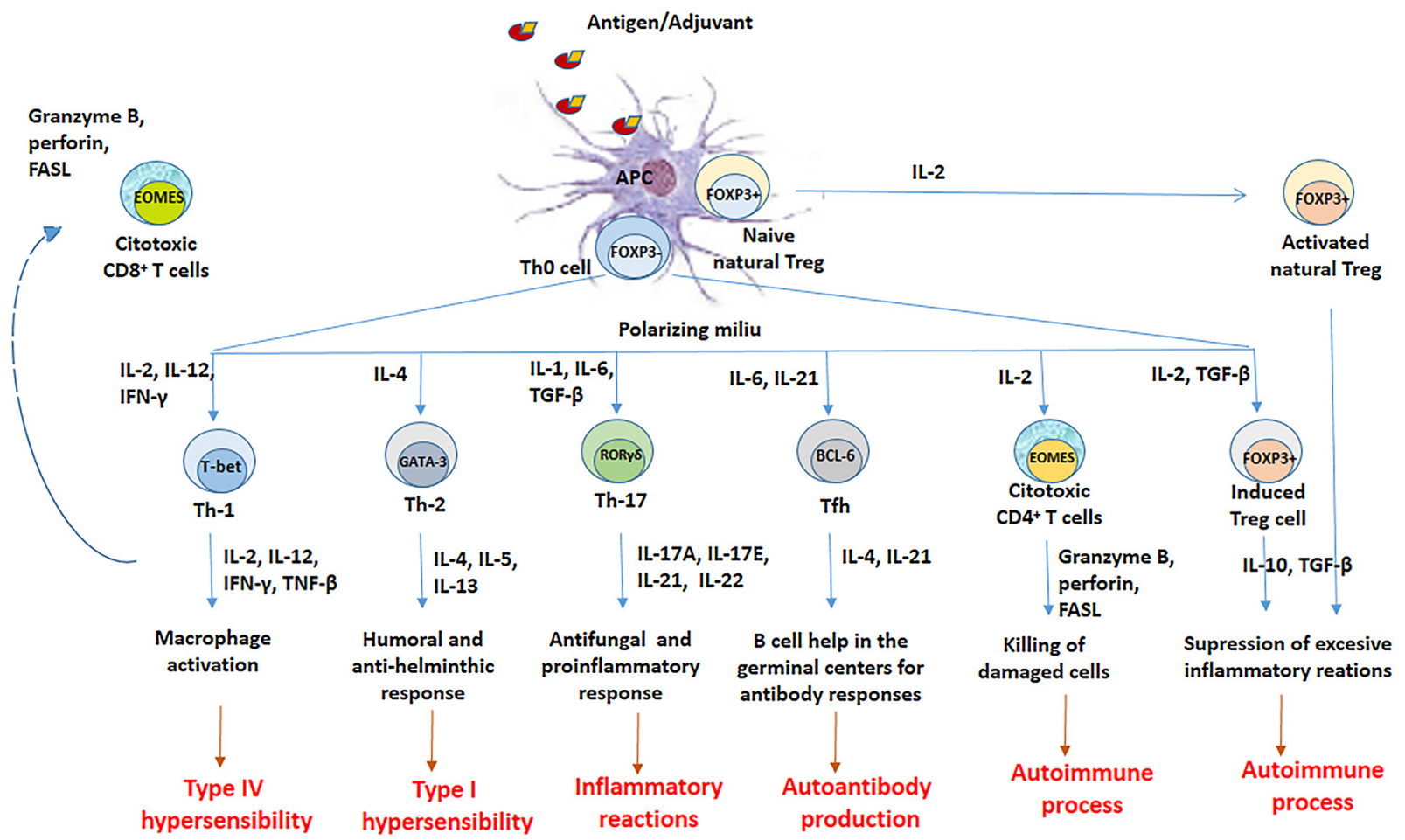

Fig. 1. CD4 + T cell polarization into functionally distinct cell lines after antigen/adjuvant stimulation and associated immunotoxicity reactions. After antigen/adjuvant interaction with antigen presentating cells (APCs) and presentation to naive T cells, natural Treg are activated while Th0 cells can be polarized to different Th subsets cells. The CD4 + T cell polarization is driven by the nature of the antigen and the adjuvant, the way of administration and the genetic background. Immune polarization optimize the immune response but under misregulated conditions, different immunotoxic responses (highlighted in red words) can be induced. 




Fig. 2. Overview of immunotoxic reactions induced by adjuvants.

A) Transitory local inflammation and B) acute phase response, both occurring during the first hours post-vaccination. C) Local delayed-type hypersensitivity and D) selected autoimmune reactions occurring after $72 \mathrm{~h}$ post-vaccination*.

* Autoimmune reactions after human prophylactic vaccine are regarded rare adverse events and the relation of causality in many cases is still under debate.

that appear in the first $24 \mathrm{~h}$ and usually do not last more than $72 \mathrm{~h}$. They can be local or systemic and some of them are rarely observed [3] (Fig. 2A and B).

\subsection{Transitory local inflammation}

Immediately after the first contact of the adjuvant formulation with the tissue, a chemical irritation can occur due to a non-physiological $\mathrm{pH}$, osmolarity or by direct cytotoxicity $[6,11,12]$. Adjuvants such as alum, saponins (e.g. Quil A and QS21-saponin fractions purified from the soapbark tree Quillaja saponaria Molina); immune-stimulatory complexes (ISCOMs); Iscomatrix) and some emulsions, produce direct cytolysis in the inoculation site associated to immediate local pain, congestion, and focal inflammation [12]. Findings of a recent study showed that direct irritant effect of cytotoxic adjuvants detected in vitro is directly associated to severe local reactions in the inoculation site in vivo [13]. For that reason, cytotoxic adjuvants are particularly contraindicated for mucosal vaccination.

The cytotoxicity of emulsions containing mineral salts is due to the presence of short chain hydrocarbons with detergent-like effects, dissolving the lipid bilayer of the cell membrane. Mineral oils are a mix of hydrocarbons with carbon chains of different length. Short chains induce local reactions, whereas longer chains (> C14) are safer, but less efficient as adjuvants. The emulsifiers used in water/oil emulsions, such as mannide monooleate can produce cytotoxic effects through enzymatic breakdown of native lipid chains releasing toxic fatty acids [6]. Other well-known cytotoxic adjuvants are the above-cited saponins that interact with cell membranes leading to cell lysis [14]. Surface activity responsible for foaming properties, as well as some others biological functions, including haemolytic activity of saponins, are attributed to their amphiphilic nature, which results from the presence of a hydrophilic sugar moiety, and a hydrophobic genin (called sapogenin). This structure facilitates the formation of complexes with cell membrane cholesterol leading to pore formation and cell permeabilization [15].

Adjuvants causing cytotoxicity can activate the innate immune response through of molecules released from injured cells named damageassociated molecular patterns (DAMPs). Some of the best-known DAMPs include chromatin-associated-protein-high-mobility group box 1 (HMGb1), heat shock proteins (HSPs), and purine metabolites, such as ATP and uric acid. In addition, there are also extracellularly located DAMPs generated after matrix proteolysis by enzymes released from dying cells. They include matrix fragments, such as hyaluronan, heparan sulphate and biglycan [16].

Adjuvants causing releasing of DAMPs are known as DAMP-type adjuvants [17]. They act on monocytes, macrophages, or granulocytes to induce cytokines that generate a local immuno stimulatory environment, eventually leading to dendritic cell activation. The cytotoxicity of aluminum gels have been related to their adjuvant properties. Alum yields a direct cytotoxic effect and the DNA, acid uric and 
other intracellular molecules released from dying cells mediates alum adjuvanticity through of the pro-inflammatory nod-like receptor family, pryin domain containing-3 (NLRP3) inflammasome pathway [18].

Other important group of adjuvants, named PAMP-type adjuvants, contain in their own composition pathogen-associated molecular patterns (PAMPs) and they can directly interact with pattern recognition receptors (PRRs) in dendritic cells for their activation $[17,19]$.

Because of the activation of dendritic cells, pro-inflammatory cytokines are released, including interleukin-1 (IL-1), tumor necrosis factor (TNF)- $\alpha$, IL- 6 and neutrophil-recruiting C-X-C motif chemokines, such as CXCL1, CXCL2, CXCL5 and CXCL8 [20]. They promote neutrophil egress from the vasculature and migration into the tissue. If the initial neutrophilic response were insufficient to eliminate the inoculum, a second cascade of chemotactic signals would be stimulated to recruit additional inflammatory cells by releasing $\mathrm{C}$-C motif chemokines such as CCL3, CCL4, CCL8 and CCL20. In this way, neutrophils monocytes and macrophages collaborate to remove foreign entities [21]. Simultaneously, structural and functional modifications on local draining lymphatic vessels are induced, to allow the traffic of dendritic cells carrying antigens toward regional lymph nodes [22,23].

These early events occur during the first $24-72 \mathrm{~h}$ post-inoculation and are accompanied by a transient local inflammatory reaction characterized by redness, mild pain and swelling. It is the more frequent adverse event following vaccination [9].

Once the inflammatory stimulus has been eliminated, the ongoing inflammatory response must be resolved to prevent excessive tissue damage (Fig. 1). The uptake of apoptotic neutrophils by macrophages (efferocytosis) promotes anti-inflammatory signalling that are characterized by high production of IL-10 and transforming growth factor (TGF)- $\beta$, and low production of IL-12p40. These macrophages suppress the local inflammatory response by decreasing the production of proinflammatory cytokines and reactive oxygen species (ROS), and achieving the resolution of inflammation with tissue restoration $[24,25]$.

\subsubsection{Non frequent acute reactions in the inoculation site}

The Arthus reaction: is a local type III hypersensitivity reaction, which involves the deposition of antigen/antibody immune complexes (IC) in the walls of blood vessels, causing vasculitis with severe local inflammatory reaction. This reaction can begin 2-8 hours after antigen injection and occur in the presence of elevated levels of preformed antibodies in a previously vaccinated person. The deposition of IC triggers Fc gamma receptor-dependent inflammation, in which macrophages recognize IC and release migration inhibitory factor (MIF), which damages surrounding tissue [26]. The repeated administration of the same adjuvant in different vaccines might induce high levels of antibody directed toward the adjuvant itself, leading to the possibility of inducing an Arthus reaction [27]. However, except squalene, the majority of adjuvants do not stimulate antibody responses against themselves [28]. The Arthus reaction has been reported after the repeated administration vaccines such as: recombinant anti-hepatitis B and diphtheria/tetanus anatoxins [29,30].

Local type-1 hypersensibility reactions: Aluminum adjuvants stimulate a Th2 profile. However, in practical conditions, it has been difficult to demonstrate cases where vaccination with aluminum adjuvants has led to IgE-mediated allergy toward the vaccine antigen [27]. Recall urticarial (RU), also known as a fixed-drug recall reaction, is a localized response that occurs at the site of previous antigen injection upon re-exposure to that antigen at a remote site [31,32]. Immediate swelling, hives, and intense pruritus at the site of prior antigen injection, after re-exposure to that antigen in a remote site, characterize RU [33]. This reaction has been observed in association with peptidebased vaccines that include alum or the saponin QS-21 [33,34]. The circulation of excess unbound antigen and subsequent cross-linking with antigen-specific IgE that is bound to cutaneous mast cells previously deposited at old immunization sites, leading to histamine release is a possible mechanisms involved in RU [9].

Nicolau's syndrome (NiS): NiS is a rare local reaction that can occur following intramuscular vaccine injection, by accidental intravascular or perivascular inoculation, causing vasospasm secondary to needle prick, embolization of the injected material, or pressure from the injected material around the vessel. NiS is characterized by sudden onset of painful swelling, followed by livedoid erythema, circumscribed haemorrhagic patches and ultimately tissue necrosis [35].

\subsection{Acute systemic reactions}

\subsubsection{Acute phase response (APR)}

Acute Phase Response (APR) is a transient syndrome that summarizes different endocrine, metabolic and neurological changes as consequence of an inflammatory response. The APR is initiated when pro-inflammatory cytokines are produced in levels sufficient to reach the blood flow causing systemic effects especially in the hypothalamic-pituitary-adrenal axis, liver and hemolymphatic system [36].

Flu-like symptoms are observed during the APR. They usually appear within hours of the vaccination and generally recede without complications. Flu-like symptoms typically consists of moderate fever of $38-39^{\circ} \mathrm{C}$, exceeding $40^{\circ} \mathrm{C}$ in some cases, chills, fatigue, myalgia, headache and nausea [37]. Cytokines IL-1 $\beta$, IL-6, IL-8, TNF- $\alpha$, interferon (IFN)- $\beta$, IFN- $\gamma$, prostaglandin E2 (PGE2) and several chemokines, act as pyrogens and cause other distant reactions $[37,38]$. These mediators overflowing into the systemic circulation, can gain access to the brain through saturable transport systems, and enter the circumventricular organs through fenestrated capillaries, where they induce the production of prostaglandins, such as PGE2, a centrally controlled mediator of fever [39-41].

Genetic background can influence in the magnitude of the flu-like symptoms. Stanley et al. identified eight haplotypes in the four genes IL1A, IL1B, IL1R1 and IL18, associated with an incremented or decremented risk for development of fever post-inoculation of smallpox vaccine [42]. More recently, a significant association between singlenucleotide polymorphisms/haplotypes in IL18R1 and IL18 genes and IFN- $\gamma$ cytokine release in smallpox vaccine-induced adaptive immune response was discovered [43].

APR is manifested by the production of acute-phase proteins and the modification of drug metabolisms in the liver [36,44]. Hepatocytes respond to proinflammatory cytokines, primarily through alteration of gene transcription, to increase the production of acute-phase proteins. Several of these proteins such as C-reactive protein, fibrinogen, serum amyloid A and albumin are elevated in the serum after immunization and they are eventually used as biomarker of APR post-vaccination [45]. Another effect of the APR after vaccination is the inhibition of the drug hepatic metabolism [46-50]. The inhibition of the hepatic cytochrome p450 (CYP450) isoenzymes because of immunostimulation is involved in disturbances in the metabolism and elimination of drugs administered concurrently with increased toxicity. Cytokines such as IL1 , IL-2, IL- 6 , TNF, TGF- $\beta$ and IFNs, are involved in modulating the expression of several CYP450 isoforms [51]. Prandota reported a downregulation of CYP450 isoforms through a direct reduction in mRNA levels, protein content and catalytic activity in Freund's complete adjuvant -treated rats and proposed that polymorphisms of drugmetabolizing enzymes and cytokines may influence to drug-induced hepatotoxicity and drug pharmacokinetic in genetically sensible subjects [52]. Interestingly, there are drugs such as acetaminophen, whose toxicity in overdoses depends on the integrity of the hepatic CYP450 and the immunostimulation can reduce their toxicity [53,54].

Another mechanism that can be involved in the drug toxicity after vaccination is the reduction of drug transporter expression/activity mediated by inflammation. IL- $1 \beta$, TNF- $\alpha$, and IL- 6 that are released during an acute inflammatory process, markedly alters the expression profile of hepatic transporters in rodents and humans $[55,56]$. 


\subsubsection{Non frequent acute systemic reactions}

Vascular leak syndrome (VLS): is a major dose-limiting toxicity of cytokine therapy, including IL-2, IL-12, granulocyte-macrophagecolony-stimulating factor (GM-CSF), IL-15, and other cytokines, that are used for cancer immunotherapy [57,58]. VLS is a major drawback for the use of cytokines as adjuvants in vaccines. This reaction is characterized by an increase in vascular permeability resulting in tissue edema, weight gain, oliguria, hypotension, dyspnea and multiple organ failure [59]. Several mechanisms for VLS have been proposed. They include the activation or damage of endothelial cells and leukocytes, the release of cytokines and inflammatory mediators (e.g., IL-1, TNF- $\alpha$, components of the complement cascade), cytotoxicity of lymphokineactivated killer cells on vascular endothelial cells, perforins as well as alterations in cell-cell interactions, cell matrix adhesion and in cytoskeleton function resulting in disturbance of vascular integrity [57]. In another study, it was reported that therapeutic vaccination inducing antibodies against P277 (a 24-aa fragment of the HSP60 molecule, first discovered to be an antigen for diabetogenic T-cell clones in nonobese diabetic mice) mediates endothelial cells damage and induces VLS [60].

\section{Delayed post-vaccination reactions}

The delayed post-vaccination reactions are those that last more than $72 \mathrm{~h}$. Some of them may appear several weeks, months or even years after vaccination and they can be observed in the inoculation site or systemically (Fig. 2C and D).

\subsection{Delayed reactions in the inoculation site}

When the vaccine inoculums is not rapidly removed in the first $72 \mathrm{~h}$, a local chronic inflammation can occurs due to a delayed-type hypersensitivity (DTH) response, especially in an already primed individual. Several properties can favour a depot effect, such as poor biodegradability, high viscosity and large particle size. Adjuvants, such as aluminum salts, oil emulsions, liposomes, biodegradable polymer microspheres, and living vectors, all induce long-term antigen persistence at the administration site $[2,9]$.

The development of a typical DTH reaction involves four steps [61]. 1) Initiation: after the initial inflammatory reaction, macrophages are unable to clear the inoculum, occurring incomplete phagocytosis and macrophage fusion (giant cells). 2) Accumulation: CD4 $+\mathrm{T}$ cells are recruited to activate macrophages, B cells, and eosinophils. 3) Effector phase: Th1 cells secrete interferon- $\gamma$ (IFN- $\gamma$ ) and TNF- $\beta$ to activate microbicidal mechanisms, such as reactive oxygen species and nitric oxide in macrophages and enhance the recruitment of effector cells such as natural killer and CD8 + T cells. Histological changes include a localized area of tissue necrosis containing foreign material thought to consist of adjuvant or vaccine components. The central zone of foreign and necrotic material is bordered by macrophages and multi-nucleated giant cells, with a peripheral zone of lymphocytes and variable numbers of plasma cells and eosinophils. This lesion is often referred to as a foreign body granuloma, 4) Resolution: when the previously mentioned mechanisms fail to clear the inoculum, a process begins to prevent the expansion of tissue damage, and the granuloma becomes surrounded by fibrosis. Cytokines such as TGF- $\beta$ and IL-13, have been implicated in granulomatous fibrosis, produced by a population of granuloma homing T cells. During the resolution phase of infection, occurs tissue remodelling, orchestrated by the innate immune response [62].

\subsubsection{Rare chronic local reactions}

Macrophagic myofasciitis (MMF): MMF is a local histopathological reaction that has been observed in the human deltoid muscle and is associated with the long-term persistence of vaccine-derived aluminum hydroxide within the muscle. The MMF lesion consists of a focal infiltration of the epimysium, perimysium and perifascicular endomysium by well-circumscribed and cohesive sheets of large mononucleated cells of the monocyte/macrophage lineage. These cells are usually intermingled with a minor lymphocytic population and macrophage aggregates containing aluminum hydroxide spicules [63-65].

Tumorigenesis: A causal relationship between post-vaccination inflammation and development of different types of sarcomas, histiocytomas and cutaneous lymphoma at injection sites have been reported in association with veterinary vaccines containing alum in genetically predisposed cats, ferrets and dogs [66-72]. The exact mechanism of tumorigenesis induced by vaccine is unknown, but it is speculated that fibroblasts or myofibroblasts are stimulated by the local inflammation, triggering inactive oncogenes [73]. In humans, rare cases of cutaneous and subcutaneous pseudolymphoma have been documented after immunization with hepatitis vaccine adjuvanted with alum. Histopathological studies showed dermal and hypodermal lymphocytic follicular infiltrates with germinal centre formation. The follicles were composed of $\mathrm{B}$ cells without atypia, whereas $\mathrm{CD} 4+\mathrm{T}$ cells were predominant at the periphery. Molecular analysis revealed a polyclonal pattern of $B$ and $\mathrm{T}$ cell subsets. Histochemical staining in all cases and by microanalysis and ultrastructural studies in one case identified aluminum deposits. Associated manifestations included vitiligo and chronic fatigue with myalgia in a few cases [74].

\subsection{Delayed systemic reactions}

Delayed systemic reactions induced by immunological adjuvants have been observed under experimental conditions, while autoimmune reactions are regarded rare adverse events of preventive human vaccines.

\subsubsection{Induction or worsening of autoimmune diseases}

Induction or worsening of autoimmune diseases is one of the best examples of immunotoxic reaction by the combined effect of adjuvant/ antigen. However, there are examples of experimental autoimmunity induced by adjuvants without any joint-specific antigen [75-78]. Another clinical examples such as siliconosis, MMF, the Gulf war syndrome, and post-vaccination phenomena, that are part of the "autoimmune/inflammatory syndrome induced by adjuvants" (ASIA) [79], highlight the role of the adjuvants in the mechanisms of induction or worsening of autoimmune diseases [79-81].

In general, a classical vaccine formulation can contain all the necessary elements for triggering de novo or worsening of an already existing autoimmune disease in susceptible individuals [81]. Cryptic antigens in the vaccine, may contain mimetic epitopes with selfstructures, while the co-administered adjuvant stimulates the up-regulation of costimulatory molecules and cytokines. They promote the polyclonal activation of specific and bystanding anergic autoreactive lymphocytes reviving their potential to trigger autoimmune reactions. In addition, an epitope spreading mechanism can occur by continual damage and release of self-peptides during the inflammatory process [80].

A clear distinction should be made between autoimmunity and autoimmune disease. Autoimmune reactions underline many normal immunological processes and these events rarely develop into clinical disease due to the existing mechanisms of immune regulation. However, there are numerous reports of suspected autoimmune clinical manifestations associated with some prophylactic vaccines, several of them obtained from vaccine adverse event reporting system (VAERS) [82-84], but several cases could not be confirmed, which has created much debate [85]. Disagreements still exist and in 2015 a group of experts concluded that there is no compelling evidence supporting the association of vaccine adjuvants with autoimmunity signals. Nevertheless, they agree that future biomarkers related to autoimmune diseases may help provide better understanding and risk management in susceptible subpopulation [86].

In the case of therapeutic vaccines, other common observations show that the potential risk of a post-vaccination autoimmune event is 
real. One of the clearest examples is the development of vitiligo (an autoimmune skin reaction) in patients receiving therapeutic melanoma vaccines $[87,88]$. Fortunately, vitiligo is a self-limited reaction and it is associated with a good prognosis in terms of therapeutic effectiveness [88]. However, others systemic autoimmunity manifestations during adjuvant anti-tumor immunotherapy have been reported $[89,90]$.

\subsubsection{Embryonic immunotoxicity}

Pregnancy is a complex immunological state in which a bias toward Th2 protects the fetus and is important for a successful pregnancy while Th1 cytokine profile during pregnancy may increase the risk of abortions and foetal morphological defects [91,92]. Moreover, evidence suggests that proinflammatory cytokines increase the risk of poor neonatal outcome, independently of the direct effect of preterm labour [93]. Cytokines, natural killer cells and gamma delta T cells of maternal origin seems to be involved in processes such as foetal recognition, placental development and regulation of gene expression during organogenesis [94]. Studies revealed that injection of high doses of CpG oligodeoxynucleotides, a vaccine adjuvant inducing strong Th1 responses, to pregnant C57BL/6 mice resulted in a marked increase in foetal resorption and craniofacial/limb defects, while lower doses had little or no effect. The histological examination of the placentas showed cellular necrosis with mixed inflammation and calcification in the spongiotrophoblast layer and dysregulation of labyrinthine vascular development $[95,96]$. Another study showed that fetal resorption and preterm birth are rapidly induced in mice after intraperitoneal injection of CPG on gestational day $10-14$. In contrast, TLR9 ${ }^{-/-}$mice or mice receiving oral administration of the TLR9 inhibitor chloroquine were protected from these effects [97]. In contrast, Delannois et al. (2018) evaluated the potential reproductive and developmental toxicity of the synthetic oligodeoxynucleotide (ODN) CpG 7909, a component of GSK's AS15 immunostimulant in rat and rabbit studies following intermittent intramuscular injections. They used a dosing regimen reflecting the planned intermittent intramuscular (IM) clinical use of CpG 7909 in AS15-adjuvanted vaccines. Under the experimental conditions of these studies, no adverse effects were observed on female fertility and preand post-natal development of offspring from rats or rabbits [98].

In theory, an adjuvanted vaccine given in the early stage of pregnancy could affect the embryofoetal development through Th1-type immunity [91]. A recent review of the adverse events after hepatitis B vaccination of pregnant women reported to the Vaccine Adverse Event Reporting System (VAERS) revealed that among 192 reports describing an adverse event, the most common pregnancy-specific outcomes included spontaneous abortion in 23 reports, preterm delivery in 7 reports, and elective termination in 5 reports [99].

Despite the above described reports, there is little available information on adjuvants developmental immunotoxicity, thus teratogenic effects that may result from exposure to vaccine adjuvants require a particular attention. Special care should be taken with the preclinical models used that do not always reflect the human context. For example, it has been suggested that because of the cellular distribution of TLR9 in mice is broader than in humans; therefore, rodents exhibit a broader spectrum of cytokines, which may result in over-estimating the risk associated with CpGODNs [94]. Further studies are necessary to understand the real danger of the use of adjuvants during pregnancy.

\section{From empirical to rationally designed adjuvants for human vaccine}

The history of adjuvants began at the beginning of the 20th century. In 1925, Gaston Ramon tested in an empirical fashion substances such as agar, tapioca, lecithin starch oil, saponin, salts of calcium and magnesium, killed Salmonella typhi and even bread crumbs to enhance the immune response to diphtheria subunit toxoid. Around the same time, Alexander Glenny and co-workers demonstrated that diphtheria toxoid precipitated with aluminum salts significantly enhanced the immune response to the toxoid [101]. The successful results of human trials with diphtheria toxoid precipitated with alum were published in 1934 [102] and with tetanus toxoid in 1936 [103]. However, at that time some early alum preparations also showed poor reproducibility with failed clinical trials [104]. Aluminum salts were the only adjuvant in use in several licensed vaccines for approximately 70 years. However, despite its extensive use, the immune mechanisms of action of aluminum remains incompletely understood [105,106].

The first vaccine formulated with an adjuvant other than aluminum was Epaxal ${ }^{\circledast}$, a hepatitis A vaccine licensed in the mid-1990 s, which uses a virosome adjuvant system [107]. In the last two decades, others adjuvants have been included in licensed vaccines. Adjuvant System 04 (AS04; GlaxoSmithKline [GSK]) is an adjuvant combination that contain (3-deacyl-monophosphoryl lipid A) derived from LPS from Salmonella Minnesota and aluminum salts. AS04 is used in vaccines against hepatitis B and human papillomavirus (HPV). Adjuvant System 03 (AS03; GSK) is another combination adjuvant composed of $\mathrm{d} 1-\alpha$ tocopherol (vitamin E), squalene and polysorbate 80 , and it is used in anti-influenza vaccines. Other adjuvants that are being used in licenced vaccines is the oil-in-water emulsion adjuvant MF59 (Novartis) that use squalene, a naturally occurring and readily metabolized oil. MF59 induce robust humoral and cellular immune responses in influenza-seasonal and pandemic vaccines. Montanide ISA 51 (ISA 51; Seppic) contain mineral oil DRAKEOL 6 VR Surfactant mannide-mono-oleate, and it is used for therapeutic vaccines [108,109]

Numerous adjuvants have been evaluated for many years in antiviral, antibacterial and antifungal experimental vaccines $[1,2,6,110]$. However, the vast majority have not been used in human vaccines for safety reasons. New generations of adjuvants are based on well-defined structures and mechanisms of action. Frequently, they are called molecular adjuvants and comprise agonist of pattern recognition receptors, plasmid-encoded signalling molecules including cytokines, chemokines, immune costimulatory molecules, inhibitors of immune suppressive pathways, post-transcriptional gene silencing process triggered by double-stranded short hairpin RNA (shRNA) structures and immune checkpoint modulators.

Despite their relative simplicity in comparison with classical adjuvants, a large part of experimental molecular adjuvants exhibited different types of toxicity or low efficacy that limit their use in humans $[8,111]$. A plasmid vector (pATRex) is a genetic adjuvant encompassing the DNA sequence for the von Willebrand I/A domain (VWA) of tumor endothelial marker-8 (TEM8, alias Anthrax Toxin Receptor-1). Studies showed that pATRex enhanced immune protection against various tumors when given in combination with DNA encoding tumor associated antigens (TAA) [112]. pATRex promotes the formation of protein aggregates that induce frustrated autophagy leading to caspase activation and cell death with the consequent activation of innate immune pathways leading to enhanced vaccine immunogenicity [113]. However, several reports evidenced that intramuscular injection of pATRex in mice triggers severe bone loss (osteoporosis), amyloid and aggregosome associated disorders, associated to chronically over-activated innate immune system $[114,115]$. Other molecular adjuvants have been used to modulate the function of regulatory $\mathrm{T}$ cells (Tregs) by different mechanisms including Treg depletion, disruption of Tregs homing or Tregs differentiation to Th17 cells (plasticity) and checkpoint receptor inhibitors leading to Tregs functional inhibition. Several of these adjuvants induced diverse autoimmune manifestations while others exhibited a promising balance efficacy/safety [8].

\section{Conclusions}

Much effort has been devoted to unravel the mechanisms of action of adjuvants, however almost exclusively with a focus on efficacy while only a relatively small number of studies have deeply investigated relevant toxicity mechanisms. Essentially, the mechanisms that are responsible for the immunostimulating effects are, at the same time, 
responsible of the adverse effects. In this context, it is often very difficult to establish the boundaries between immunostimulation and immunotoxicity to achieve high efficacy with minimal toxicity. Considering furthermore the wide diversity of adjuvants, a reductionist analysis of efficacy/toxicity is not possible. Therefore, each analysis must be done case by case. One of the key challenges for the development of future adjuvants and adjuvanted vaccines is the identification of reliable biomodels and biomarkers with the potential to predict immunogenicity, efficacy and safety, as well as subject-specific signatures (e.g., genetic makeup) [95]. Growing strategies of rational design of adjuvants are contributing to improve the efficacy/safety balance of contemporary and future vaccines.

\section{Author contributions}

ABD: conceived, designed and wrote the manuscript, DTM: compiled updated information and wrote part of the manuscript, IZC: supervised research and wrote part of the manuscript.

\section{Conflicts of interest}

The authors have declared that no conflict of interest exists.

\section{Acknowledgements}

We would like to thank Lucija Tomljenovic for helpful comments and suggestions of the manuscript.

\section{References}

[1] D.T. O'Hagan, C.B. Fox, New generation adjuvants-from empiricism to rational design, Vaccine 33 (Suppl. 2) (2015) B14-B20.

[2] N. Petrovsky, Comparative safety of vaccine adjuvants: a summary of current evidence and future needs, Drug Saf. 38 (11) (2015) 1059-1074.

[3] A. Batista-Duharte, E.B. Lindblad, E. Oviedo-Orta, Progress in understanding adjuvant immunotoxicity mechanisms, Toxicol. Lett. 203 (2) (2011) 97-105.

[4] D. Mohanan, B. Slutter, M. Henriksen-Lacey, W. Jiskoot, J.A. Bouwstra, Y. Perrie, et al., Administration routes affect the quality of immune responses: a cross-sectional evaluation of particulate antigen-delivery systems, J. Control Release 147 (3) (2010) 342-349.

[5] O. Pérez, B. Romeu, O. Cabrera, E. González, A. Batista-Duharte, A. Labrada, R. Pérez, L.M. Reyes, W. Ramírez, S. Sifontes, N. Fernández, M. Lastre, adjuvants are key factors for the development of future vaccines: lessons from the finlay adjuvant platform, Front. Immunol. 4 (2013) 407.

[6] R.K. Gupta, E.H. Relyveld, E.B. Lindblad, B. Bizzini, S. Ben-Efraim, C.K. Gupta, Adjuvants - a balance between toxicity and adjuvanticity, Vaccine 11 (3) (1993) 293-306.

[7] J. Honegr, R. Dolezal, D. Malinak, M. Benkova, O. Soukup, J.S.F.D. Almeida, T.C.C. Franca, K. Kuca, R. Prymula, Rational design of a New class of toll-like receptor 4 (TLR4) tryptamine related agonists by means of the structure- and ligand-based virtual screening for vaccine adjuvant Discovery, Molecules 23 (January (1)) (2018) pii: E102.

[8] A. Batista-Duharte, D. Téllez-Martínez, D.L.P. Fuentes, I.Z. Carlos, Molecular adjuvants that modulate regulatory t cell function in vaccination: a critical appraisal, Pharmacol. Res. 129 (2018) 237-250.

[9] A. Batista-Duharte, D. Portuondo, I.Z. Carlos, O. Perez, An approach to local immunotoxicity induced by adjuvanted vaccines, Int. Immunopharmacol. 17 (3) (2013) 526-536.

[10] F. Liang, G. Lindgren, K.J. Sandgren, E.A. Thompson, J.R. Francica, A. Seubert, E. De Gregorio, S. Barnett, D.T. O’Hagan, N.J. Sullivan, R.A. Koup, R.A. Seder, K. Loré, Vaccine priming is restricted to draining lymph nodes and controlled by adjuvant-mediated antigen uptake, Sci. Transl. Med. 9 (393) (2017) pii: eaal2094.

[11] N. Goto, H. Kato, J. Maeyama, M. Shibano, T. Saito, J. Yamaguchi, et al., Local tissue irritating effects and adjuvant activities of calcium phosphate and aluminium hydroxide with different physical properties, Vaccine 15 (12-13) (1997) 1364-1371.

[12] D.C. Waite, E.W. Jacobson, F.A. Ennis, R. Edelman, B. White, R. Kammer, et al., Three double-blind, randomized trials evaluating the safety and tolerance of different formulations of the saponin adjuvant QS-21, Vaccine 19 (28-29) (2001) 3957-3967.

[13] A. Batista-Duharte, G. Jorge Murillo, U.M. Perez, E.N. Tur, D.F. Portuondo, B.T. Martinez, et al., The hen's egg test on chorioallantoic membrane: an alternative assay for the assessment of the irritating effect of vaccine adjuvants, Int. J. Toxicol. 35 (6) (2016) 627-633.

[14] H.X. Sun, Y. Xie, Y.P. Ye, Advances in saponin-based adjuvants, Vaccine 27 (12) (2009) 1787-1796.
[15] I. Podolak, A. Galanty, D. Sobolewska, Saponins as cytotoxic agents: a review, Phytochem. Rev. 9 (3) (2010) 425-474.

[16] G.Y. Chen, G. Nunez, Sterile inflammation: sensing and reacting to damage, Nat. Rev. Immunol. 10 (12) (2010) 826-837.

[17] B.S. Powell, A.K. Andrianov, P.C. Fusco, Polyionic vaccine adjuvants: another look at aluminium salts and polyelectrolytes, Clin. Exp. Vaccine Res. 4 (1) (2015) 23-45.

[18] P. He, Y. Zou, Z. Hu, Advances in aluminum hydroxide-based adjuvant research and its mechanism, Hum. Vaccines Immunother. 11 (2) (2015) 477-488.

[19] T. Olafsdottir, M. Lindqvist, A.M. Harandi, Molecular signatures of vaccine adjuvants, Vaccine 33 (40) (2015) 5302-5307.

[20] M.D. Turner, B. Nedjai, T. Hurst, D.J. Pennington, Cytokines and chemokines: at the crossroads of cell signalling and inflammatory disease, Biochim. Biophys. Acta 1843 (11) (2014) 2563-2582.

[21] O. Soehnlein, L. Lindbom, Phagocyte partnership during the onset and resolution of inflammation, Immunology 10 (2010) 427-439.

[22] M.A. Swartz, J.A. Hubbell, S.T. Reddy, Lymphatic drainage function and its immunological implications: from dendritic cell homing to vaccine design, Semin. Immunol. 20 (2) (2008) 147-156.

[23] M.R. Neeland, M.J. Elhay, D.R. Powell, F.J. Rossello, E.N. Meeusen, M.J. de Veer Transcriptional profile in afferent lymph cells following vaccination with liposomes incorporating CpG, Immunology 144 (3) (2015) 518-529.

[24] M.C. Greenlee-Wacker, Clearance of apoptotic neutrophils and resolution of inflammation, Immunol. Rev. 273 (1) (2016) 357-370.

[25] M.R. Elliott, K.M. Koster, P.S. Murphy, Efferocytosis signaling in the regulation of macrophage inflammatory responses, J. Immunol. 198 (4) (2017) 1387-1394.

[26] C.N. Paiva, R.H. Arras, E.S. Magalhaes, L.S. Alves, L.P. Lessa, M.H. Silva, et al, Migration inhibitory factor (MIF) released by macrophages upon recognition of immune complexes is critical to inflammation in arthus reaction, J. Leukoc. Biol. 85 (2009) 855-861.

[27] E.B. Lindblad, Safety evaluation of vaccine adjuvants, in: M. Singh (Ed.), Vaccine Adjuvants and Delivery Systems, Wiley-Interscience, Hoboken, NJ, 2007, pp. 421-444.

[28] P.B. Asa, R.B. Wilson, R.F. Garry, Antibodies to squalene in recipients of anthrax vaccine, Exp. Mol. Pathol. 73 (1) (2002) 19-27.

[29] H. Froehlich, R. Verma, Arthus reaction to recombinant hepatitis B virus vaccine, Clin. Infect. Dis. 33 (6) (2001) 906-908.

[30] C. Ponvert, Allergic and non-allergic hypersensitivity reactions to toxoid-containing vaccines, Arch. Pediatr. 16 (4) (2009) 391-395.

[31] M. Karaayvaz, N. Ozanguc, Recall urticaria: a case report, J. Allergy Clin. Immunol. 97 (1996) 1419-1420.

[32] K. Rinn, K. Schiffman, H.O. Otero, M.L. Disis, Antigen-specific recall urticaria to peptide-based vaccine, Allergy Clin. Immunol. 104 (1999) 240-242.

[33] J.K. Simon, R. Edelman, Clinical evaluation of adjuvants, in: V.E. Schijns, D.T. O'Hagan (Eds.), Immunopotentiators in Modern Vaccines, Academic Press, Burlington, MA, 2006, pp. 319-342.

[34] R. Edelman, S.S. Wasserman, J.G. Kublin, S.A. Bodison, E.H. Nardin, G.A. Oliveira, et al., Immediate-type hypersensitivity and other clinical reactions in volunteers immunized with a synthetic multi-antigen peptide vaccine (PfCS-MAPINYU) against Plasmodium falciparum sporozoites, Vaccine 21 (2002) 269-280.

[35] A.K. Kienast, D. Mentze, P.H. Hoeger, Nicolau's syndrome induced by intramuscular vaccinations in children: report of seven patients and review of the literature, Clin. Exp. Dermatol. 33 (5) (2008) 555-558.

[36] A. Batista-Duharte, D. Portuondo, O. Perez, I.Z. Carlos, Systemic immunotoxicity reactions induced by adjuvanted vaccines, Int. Immunopharmacol. 20 (1) (2014) $170-180$.

[37] J. Descotes, T. Vial, Flu-like syndrome and cytokines, in: R.V. House, J. Descotes (Eds.), Cytokines in Human Health - Immunotoxicology, Pathology, and Therapeutic Applications, Humana Press, Totowa, NJ, 2007, pp. 193-290.

[38] T. Nakayama, Y. Kashiwagi, H. Kawashima, T. Kumagai, K.J. Ishii, T. Ihara, Alumadjuvanted H5N1 whole virion inactivated vaccine (WIV) enhanced inflammatory cytokine productions, Vaccine 30 (26) (2012) 3885-3890.

[39] B. Conti, I. Tabarean, C. Andrei, T. Bartfai, Cytokines and fever, Front. Biosci. 9 (2004) 1433-1449.

[40] C. Cao, K. Matsumura, K. Yamagata, Y. Watanabe, Involvement of cyclooxygenase2 in LPS-induced fever and regulation of its mRNA by LPS in the rat brain, Am. J. Physiol Regul. Integr. Comp. Physiol. 272 (1997) R1712-R1725.

[41] R. Dantzer, J.C. O'Connor, G.G. Freund, R.W. Johnson, K.W. Kelley, From in flammation to sickness and depression: when the immune system subjugates the brain, Nat. Rev. Neurosci. (2008) 46-56.

[42] S.L. Stanley, S.E. Frey, P. Taillon-Miller, J. Guo, R.D. Miller, D.C. Koboldt, et al., The immunogenetics of smallpox vaccination, J. Infect. Dis. 196 (2) (2007) 212-219.

[43] I.G. Ovsyannikova, I.H. Haralambieva, R.B. Kennedy, M.M. O’Byrne, V.S. Pankratz, G.A. Poland, Genetic variation in IL18R1 and IL18 genes and interferon $\gamma$ ELISPOT response to smallpox vaccination: an unexpected relationship, J. Infect. Dis. 208 (9) (2013) 1422-1430.

[44] E.J. Gribble, P.V. Sivakumar, R.A. Ponce, S.D. Hughes, Toxicity as a result of immunostimulation by biologics, Expert Opin. Drug Metab. Toxicol. 3 (2) (2007) 209-234.

[45] M.D. Green, Acute phase responses to novel, investigational vaccines in toxicology studies: the relationship between C-reactive protein and other acute phase proteins, Int. J. Toxicol. 34 (5) (2015) 379-383.

[46] M. Levine, M.W. Jones, M. Gribble, Increased serum phenytoin concentration following influenza vaccination, Clin. Pharm. 3 (1984) 505-509.

[47] K.W. Renton, J.D. Gray, R.I. Hall, Decreased elimination of theophylline after 
influenza vaccination, Can. Med. Assoc. J. 123 (1980) 288-290.

[48] P. Kramer, C.J. McClain, Depression of aminopyrine metabolism by influenza vaccination, N. Engl. J. Med. 305 (1981) 1262-1264.

[49] P. Pellegrino, C. Carnovale, V. Perrone, D. Salvati, M. Gentili, T. Brusadelli, et al., On the possible interaction between vaccines and drugs, Eur J. Clin. Pharmacol. 70 (2014) 369-371.

[50] K.H. Yang, Y.S. Jung, D.Y. Lee, Time-dependent effects of Klebsiella pneumoniae endotoxin (KPLPS) on the pharmacokinetics of theophylline in rats: return of the parameters in 96-hour KPLPS rats to the control levels, Drug Metab. Dispos. 36 (2008) 811-815.

[51] K.W. Renton, Alteration of drug biotransformation and elimination during infection and inflammation, Pharmacol. Ther. 92 (2001) 147-163.

[52] J. Prandota, Important role of proinflammatory cytokines/other endogenous substances in drug-induced hepatotoxicity: depression of drug metabolism during infections/inflammation states, and genetic polymorphisms of drug-metabolizing enzymes/cytokines may markedly contribute to this pathology, Am. J. Ther. 12 (2005) 254-261.

[53] H.Z. Toklu, A.O. Sehirli, A. Velioğlu-Oğunc, S. Cetinel, G. Sener, Acetaminopheninduced toxicity is prevented by beta-D-glucan treatment in mice, Eur. J. Pharmacol. 543 (1-3) (2006) 133-140.

[54] N.P. Garcia, O.F. Lores, D.P. Fuentes, D.T. Martinez, J.B. Hernandez, et al., Reduction of hepatotoxicity induced by acetaminophen overdoses in a mouse model of inflammation induced by Freund's adjuvants, J. Allergy Ther. 5 (2014) 183.

[55] O. Fardel, M. Le Vee, Regulation of human hepatic drug transporter expression by pro-inflammatory cytokines, Expert Opin. Drug. Metab. Toxicol. 5 (12) (2009) 1469-1481.

[56] A.M. Cressman, V. Petrovic, M. Piquette-Miller, Inflammation-mediated changes in drug transporter expression/activity: implications for therapeutic drug response, Expert Rev. Clin. Pharmacol. 5 (1) (2012) 69-89.

[57] R.G. Baluna, Cytokine-induced vascular leak syndrome, in: R.V. House, J. Descotes (Eds.),Cytokines in human health: immunotoxicology, pathology, and therapeutic applications, Humana Press, 2007, pp. Totowa, NJ, 2007, pp. 205-231. Vaccine 30 (26) (2012) 3885-3890.

[58] K.C. Conlon, E. Lugli, H.C. Welles, S.A. Rosenberg, A.T. Fojo, J.C. Morris, et al., Redistribution, hyperproliferation, activation of natural killer cells and CD8 T cells, and cytokine production during first-in-human clinical trial of recombinant human interleukin-15 in patients with cancer, J. Clin. Oncol. 33 (1) (2015) 74-82.

[59] N.K. Damle, L.V. Doyle, IL-2-activated human killer lymphocytes but not their secreted products mediate increase in albumin flux across cultured endothelial monolayers. Implications for vascular leak syndrome, J. Immunol. 142 (8) (1989) 2660-2669.

[60] L. Yong, S. Yunxiao, X. Qiyan, Z. Yu, H. Jing, D.J. Mekoo, et al., Immunization with P277 induces vascular leak syndrome in C57BL/6 mice via endothelial damage, Autoimmunity 43 (8) (2010) 654-663.

[61] D.O. Co, L.H. Hogan, S. Il-Kim, M. Sandor, T cell contribution to the different phases of granuloma formation, Immunol. Lett. 92 (2004) 135-142.

[62] A. Micera, B.O. Balzamino, A.D. Zazzo, F. Biamonte, G. Sica, S. Bonini, Toll-like receptors and tissue remodeling: the pro/cons recent findings, J. Cell. Physiol. 231 (3) (2016) 531-544.

[63] R.K. Gherardi, M. Coquet, P. Cherin, L. Belec, P. Moretto, P.A. Dreyfus, Macrophagic myofasciitis lesions assess long-term persistence of vaccine-derived aluminium hydroxide in muscle, Brain 124 (2001) 1821-1831.

[64] R.K. Gherardi, F.J. Authier, Macrophagic myofasciitis: characterization and pathophysiology, Lupus 21 (2012) 184-189.

[65] F. Verdier, R. Burnett, C. Michelet-Habchi, P. Moretto, F. Fievet-Groyne, E. Sauzeat, Aluminium assay and evaluation of the local reaction at several time points after intramuscular administration of aluminium containing vaccines in the Cynomolgus monkey, Vaccine 23 (11) (2005) 1359-1367.

[66] P. Roccabianca, G. Avallone, A. Rodriguez, L. Crippa, E. Lepri, C. Giudice, M. Caniatti, P.F. Moore, V.K. Affolter, Cutaneous lymphoma at injection sites: pathological. Immunophenotypical and molecular characterization in 17 cats, Vet. Pathol. 53 (4) (2016) 823-832.

[67] I. Porcellato, L. Menchetti, C. Brachelente, M. Sforna, A. Reginato, E. Lepri, L. Mechelli, Feline injection-site sarcoma, Vet. Pathol. 54 (2) (2017) 204-211.

[68] M.J. Hendrick, J.J. Brooks, Postvaccinal sarcomas in the cat: histology and immunohistochemistry, Vet. Pathol. 31 (1994) 126-129.

[69] J.S. Munday, N.L. Stedman, L.J. Richey, Histology and immunohistochemistry of seven ferret vaccination-site fibro-sarcomas, Vet. Pathol. 40 (2003) 288-293.

[70] M. Vascellari, E. Melchiotti, M.A. Bozza, F. Mutinelli, Fibrosarcomas at presumed sites of injection in dogs: characteristics and comparison with nonvaccination site fibrosarcomas and feline post-vaccinal fibrosarcomas, J. Vet. Med. A 50 (2003) 286-291.

[71] P.R. Nambiar, M.L. Jackson, J.A. Ellis, B.J. Chelack, B.A. Kidney, D.M. Haines, Immunohistochemical detection of tumor suppressor gene p53 protein in feline injection site-associated sarcomas, Vet. Pathol. 38 (2) (2001) 236-238.

[72] P.H. Kass, W.L. Spangler, M.J. Hendrick, L.D. McGill, D.G. Esplin, S. Lester, et al., Multicenter case-control study of risk factors associated with development of vaccine associated sarcomas in cats, J. Am. Vet. Med. Assoc. 223 (2003) 1283-1299.

[73] F. Colotta, P. Allavena, A. Sica, C. Garlanda, A. Mantovani, Cancer-related in flammation, the seventh hallmark of cancer: links to genetic instability, Carcinogenesis 30 (2009) 1073-1081.

[74] E. Maubec, L. Pinquier, M. Viguier, F. Caux, E. Amsler, S. Aractingin, et al., Vaccination-induced cutaneous pseudolymphoma, J. Am. Acad. Dermatol. 52 (4) (2005) 623-629.
[75] C.M. Pearson, Development of arthritis, periarthritis and periostitis in rats given adjuvants, Proc. Soc. Exp. Biol. Med. 91 (1956) 95-101.

[76] L.M. Stasiuk, M. Ghoraishian, C. Elson, S.J. Thompson, Pristane-induced arthritis is CD4 + T cell-dependent, Immunology 90 (1997) 81-86.

[77] A. Billiau, P. Matthys, Modes of action of Freund's adjuvants in experimental models of autoimmune diseases, J. Leukoc. Biol. 20 (2001) 849-860.

[78] Y. Kuroda, D.C. Nacionales, J. Akaogi, W.H. Reeves, M. Satoh, Autoimmunity induced by adjuvant hydrocarbon oil components of vaccine, Biomed. Pharmacother. 58 (5) (2004) 325-337.

[79] Y. Shoenfeld, N. Agmon-Levin, 'ASIA' autoimmune/inflammatory syndrome induced by adjuvants, J. Autoimmun. 36 (1) (2011) 4-8.

[80] P. Pellegrino, E. Clementi, S. Radice, On vaccine's adjuvants and autoimmunity: current evidence and future perspectives, Autoimmun. Rev. 14 (10) (2015) 880-888.

[81] B.A. Waisbren, Acquired autoimmunity after viral vaccination is caused by molecular mimicry and antigen complementarity in the presence of an immunologic adjuvant and specific HLA patterns, Med. Hypotheses 70 (2) (2008) 346-348.

[82] H. Orbach, N. Agmon-Levin, G. Zandman-Goddard, Vaccines and autoimmune diseases of the adult, Discov. Med. 9 (45) (2010) 90-97.

[83] D.A. Geier, M.R. Geier, Quadrivalent human papillomavirus vaccine and autoimmune adverse events: a case-control assessment of the vaccine adverse event reporting system (VAERS) database, Immunol. Res. 65 (1) (2017) 46-54.

[84] D.A. Geier, M.R. Geier, A case-control study of serious autoimmune adverse events following hepatitis B immunization, Autoimmunity 38 (4) (2005) 295-301.

[85] A. Batista-Duharte, Vaccines and autoimmunity: a strange association under debate, Rev. Peru Med. Exp. Salud Publica 29 (2) (2012) 265-271.

[86] J.W. van der Laan, S. Gould, J.Y. Tanir, ILSI HESI vaccines and adjuvants safety project committee. safety of vaccine adjuvants: focus on autoimmunity, Vaccine 33 (13) (2015) 1507-1544.

[87] K.T. Byrne, M.J. Turk, New perspectives on the role of vitiligo in immune responses to melanoma, Oncotarget 2 (9) (2011) 684-694.

[88] H.E. Teulings, J. Limpens, S.N. Jansen, A.H. Zwinderman, J.B. Reitsma, P.I. Spuls, R.M. Luiten, Vitiligo-like depigmentation in patients with stage III-IV melanoma receiving immunotherapy and its association with survival: a systematic review and meta-analysis, J. Clin. Oncol. 33 (7) (2015) 773-781.

[89] A.A. Tarhini, D. Shin, S.J. Lee, J. Stuckert, C.A. Sander, J.M. Kirkwood, Serologic evidence of autoimmunity in E2696 and E1694 patients with high-risk melanoma treated with adjuvant interferon alfa, Melanoma Res. 24 (2) (2014) 150-157.

[90] H. Gogas, J. Ioannovich, U. Dafni, C. Stavropoulou-Giokas, K. Frangia, D. Tsoutsos, P. Panagiotou, A. Polyzos, O. Papadopoulos, A. Stratigos, C. Markopoulos, D. Bafaloukos, D. Pectasides, G. Fountzilas, J.M. Kirkwood, Prognostic significance of autoimmunity during treatment of melanoma with interferon, N. Engl. J. Med. 354 (7) (2006) 709-718.

[91] R. Raghupathy, Th1-type immunity is incompatible with successful pregnancy, Immunol. Today 18 (1997) 478-482.

[92] M. Makhseed, R. Raghupathy, F. Azizieh, A. Omu, E. Al-Shamali, L. Ashkanani, Th1 and Th2 cytokine profiles in recurrent aborters with successful pregnancy and with subsequent abortions, Hum. Reprod. 16 (10) (2001) 2219-2226.

[93] L. Sykes, D.A. MacIntyre, X.J. Yap, S. Ponnampalam, T.G. Teoh, P.R. Bennett, Changes in the Th1:Th2 cytokine bias in pregnancy and the effects of the antiinflammatory cyclopentenone prostaglandin 15 -deoxy- $\Delta(12,14)$-prostaglandin $\mathrm{J} 2$, Mediators Inflamm. (2012) 2012: 416739.

[94] J. Szekeres-Bartho, Immunological relationship between the mother and the fetus, Int. Rev. Immunol. 21 (2002) 471-495.

[95] M.R. Prater, V.J. Johnson, D.R. Germolec, M.I. Luster, S.D. Holladay, Maternal treatment with a high dose of CpG ODN during gestation alters fetal craniofacial and distal limb development in C57BL/6 mice, Vaccine 24 (2006) 263-271.

[96] J.E. Thaxton, R. Romero, S. Sharma, TLR9 activation coupled to IL-10 deficiency induces adverse pregnancy outcomes, J. Immunol. 183 (2) (2009) 1144-1154.

[97] A. Scharfe-Nugent, S.C. Corr, S.B. Carpenter, L. Keogh, B. Doyle, C. Martin K.A. Fitzgerald, S. Daly, J.J. O'Leary, L.A. O'Neill, TLR9 provokes inflammation in response to fetal DNA: mechanism for fetal loss in preterm birth and preeclampsia, J. Immunol. 188 (11) (2012) 5706-5712.

[98] F. Delannois, C. Planty, G. Giordano, E. Destexhe, D. Stanislaus, F.T. Da Silva, J.U. Stegmann, K. Thacker, L. Reynaud, N. Garçon, L. Segal, Signal management in pharmacovigilance and human risk assessment of CpG 7909, integrating embryofetal and post-natal developmental toxicity studies in rats and rabbits, Reprod. Toxicol. 75 (2018) 110-120.

[99] P.L. Moro, Y. Zheteyeva, F. Barash, P. Lewis, M. Cano, Assessing the safety of hepatitis B vaccination during pregnancy in the vaccine adverse event reporting system (VAERS), 1990-2016, Vaccine 36 (1) (2018) 50-54.

[101] A. Glenny, C. Pope, H. Waddington, U. Falacce, The antigenic value of toxoid precipitated by potassium alum, J. Pathol. Bacteriol. 29 (1926) 31-40.

[102] J. White, Diphtheria toxoid: comparative immunizing value with and without alum as indicated by schick test, J. Am. Med. Assoc. 102 (1934) 915.

[103] F. Jones, Studies on tetanus toxiod i: the antitoxic titer of human subjects following immunization with tetanus toxoid and tetanus alum precipitated toxoid, J. Immunol. 30 (1936) 115.

[104] V. Volk, Diphtheria immunization with fl uid toxoid and alum precipated toxiod, Am. J. Public Health 32 (1942) 690.

[105] P. Marrack, A.S. McKee, M.W. Munks, Towards an understanding of the adjuvant action of aluminium, Nat. Rev. Immunol. 9 (2009) 287-293.

[106] T.R. Ghimire, The mechanisms of action of vaccines containing aluminum adjuvants: an in vitro vs in vivo paradigm, Springerplus 4.1 (2015) 181.

[107] P.A. Bovier, Epaxal: a virosomal vaccine to prevent hepatitis a infection, Expert Rev. Vaccines 7 (2008) 1141-1150. 
[108] O. Pérez, A. Batista-Duharte, E. González, C. Zayas, J. Balboa, M. Cuello, O. Cabrera, M. Lastre, V.E. Schijns, Human prophylactic vaccine adjuvants and their determinant role in new vaccine formulations, Braz. J. Med. Biol. Res. 45 (8) (2012) 681-692.

[109] A. Di Pasquale, S. Preiss, F. Tavares Da Silva, N. Garçon, Vaccine adjuvants: from 1920 to 2015 and beyond, Vaccines (Basel). 3 (2) (2015) 320-343.

[110] D.L. Portuondo, L.S. Ferreira, A.C. Urbaczek, A. Batista-Duharte, I.Z. Carlos, Adjuvants and delivery systems for antifungal vaccines: current state and future developments, Med. Mycol. 53 (1) (2015) 69-89.

[111] L. Li, N. Petrovsky, Molecular adjuvants for DNA vaccines, Curr. Issues Mol. Biol. 22 (2017) 17-40

[112] P. Felicetti, M. Mennecozzi, A. Barucca, S. Montgomery, F. Orlandi, K. Manova, A.N. Houghton, P.D. Gregor, A. Concetti, F.M. Venanzi, Tumor endothelial marker 8 enhances tumor immunity in conjunction with immunization against differentiation Ag, Cytotherapy 9 (1) (2007) 23-34.

[113] M. Capitani, F. Saade, K.M. Havas, M. Angeletti, F. Concetti, D. Agas, M.G. Sabbieti, A. Concetti, F.M. Venanzi, N. Petrovsky, Plasmids encoding protein aggregation domains act as molecular adjuvants for DNA vaccines, Curr. Gene Ther. 14 (3) (2014) 161-169.

[114] D. Agas, F. Concetti, M. Capitani, G. Lacava, A. Concetti, L. Marchetti, F. Laus, A. Marchegiani, V. Azevedo, M.G. Sabbieti, F.M. Venanzi, Administration of DNA plasmid coding protein aggregating domain induces inflammatory bone loss, Curr. Gene Ther. 16 (2) (2016) 144-152.

[115] M.G. Sabbieti, G. Lacava, A. Amaroli, L. Marchetti, R. Censi, P. Di Martino, D. Agas, Molecular adjuvants based on plasmids encoding protein aggregation domains affect bone marrow niche homeostasis, Curr. Gene Ther. 17 (5) (2018) 391-397. 